\title{
DEVELOPMENT OF SUSTAINABLE FLAME RETARDANTS FOR COTTON FABRICS BY POLYMERIZATION OF TRIMETHYL PHOSPHATE WITH SUCCINIC ACID, UREA AND GLYOXAL
}

\author{
HAJI GHULAM QUTAB,${ }^{*}$ MUHAMMAD MOHSIN, ${ }^{* *}$ NAVEED RAMZAN, ${ }^{* * *}$ \\ SYED WAQAS AHMAD* and SHAHEEN SARDAR ${ }^{* *}$ \\ *Chemical Engineering Department, UET Lahore, Faisalabad Campus, Pakistan \\ ${ }^{* * *}$ Textile Engineering Department, UET Lahore, Faisalabad Campus, Pakistan \\ ${ }^{* * * *}$ Chemical Engineering Department, UET Lahore, Main Campus, Pakistan \\ 区 Corresponding author: M. Mohsin, mohsinmalikntu@yahoo.com
}

Received May 18, 2019

\begin{abstract}
This paper evaluates two sets of sustainable flame retardant recipes for cotton fabrics through polymerization of trimethyl phosphate (TMP) with succinic acid, urea and glyoxal. In the first set of recipes, succinic acid and TMP were polymerized. In the second set, urea and glyoxal were polymerized with TMP. For these recipes, the effects of temperature, initiator, and catalyst were studied under normal atmosphere, nitrogen atmosphere, and inert atmosphere. The developed recipes were applied on cotton fabric samples and evaluated in terms of char-length and char-width. Based on char-length and char-width, selected samples were tested regarding limiting oxygen index, crease recovery angle, air permeability, shrinkage, smoldering cigarette test, phosphorus concentration, formaldehyde content, antimicrobial testing, energy dispersive X-ray spectroscopy (EDX) analysis and scanning electron microscopy (SEM) analysis. The performance of the new recipes was evaluated against the formaldehyde based commercial recipes, involving Pyrovatex. The research identified two optimum recipes to be used under nitrogen atmosphere. The optimized recipe of TMP, urea and glyoxal exhibited better results than the Pyrovatex based recipes.
\end{abstract}

Keywords: hazardous chemicals, flame retardant, phosphorus, nitrogen atmosphere, char length, textile finishing

\section{INTRODUCTION}

Many social organizations have started customer awareness movements around the world. For instance, Greenpeace's Detox campaign is encouraging famous global textile brands to ensure the elimination of hazardous chemicals from the textile production and final products in their supply chain networks. ${ }^{1}$ Consequently, the top textile brands are redesigning their supply chains due to the increased concerns about hazardous chemicals. Hence, the top brands will ultimately exclude all the unsustainable suppliers. ${ }^{2}$ The textile industry involves the consumption of numerous chemicals around the world. Flame retardants are one of the major chemical finishes used in the textile materials. Cotton fabrics have many attractive properties and numerous applications. Unfortunately, they are highly flammable, which may increase the probability of horrible fire incidences. ${ }^{3-4}$ All these issues have triggered the scientific community to develop new environment-friendly flame retardants for cotton fabrics. Most of the existing commercial flame retardants involve the usage or discharge of toxic substances, such as halogens, formaldehyde, and dicyandiamide.

Halogen based flame retardants have been restricted in many countries. Still, several papers have developed halogenated flame retardants due to their effectiveness. For instance, Abou-Okeil et $a l{ }^{5}$ developed a halogen based flame retardant using phosphorusoxychloride, which was comparable to Pyrovatex based commercial flame retardants. Due to the restriction of halogenated substances in many countries, the textile industry has successfully adopted many phosphorus based durable flame retardants, such as n-methylol dimethylphosphonopropionamide (commercially known as Pyrovatex). Pyrovatex based flame retardants use or release formaldehyde during 
application or consumer use. Formaldehyde is a toxic substance, causing many health issues, including cancer. ${ }^{6}$ In addition to the halogenated and phosphorus based flame retardants, several emerging technologies, such as nanotechnology and bio-macromolecules, have offered ecofriendly alternatives. Nanotechnology based flame retardants involve several issues, such as durability and toxic nanoparticles. ${ }^{7}$ The use of bio-macromolecules (e.g. plant based and protein based) also has many disadvantages, such as lower char-length, ${ }^{8}$ unacceptable LOI, ${ }^{9-10}$ lower durability, poor washing fastness, high cost, and limited sources for bulk production. ${ }^{11}$ Such issues related to the flame retardants based on the nanotechnology and bio-macromolecules restrict their acceptance by the textile industry.

The development or modification of phosphorus based flame retardants is the current focus of the scientific community. Unfortunately, toxic substances, such as formaldehyde and dicyandiamide, have been used in the production or application of several phosphorus based flame retardants. For instance, Zheng et al. ${ }^{12}$ and Zhang et $a l .{ }^{13}$ used formaldehyde during the production of phosphorus based flame retardants. The formaldehyde release can be reduced using butane tetra carboxylic acid, but this substance has several issues, such as low tensile strength, and very high cost. ${ }^{14}$ Many papers described the development of formaldehyde-free flame retardants. Wang et al. ${ }^{11}$ developed a phosphorus based flame retardant without the use of formaldehyde. However, toxic dicyandiamide was used as a catalyst. They reported the release of ammonia during the application. Zheng et al. ${ }^{15}$ developed a phosphorus based flame retardant without the use of formaldehyde. They used methylene phosphonic acid, urea, ethanol and dicyandiamide. $\mathrm{Lu}$ et $a l .{ }^{16}$ developed formaldehyde free phosphorus based flame retardant using diphosphonic acid, hydroxyethylidene, and ethanol, while dicyandiamide was used as catalyst. Jia et al. ${ }^{17}$ developed a phosphorus based flame retardant using pentaerythritol, phosphoric acid, ethanol, urea and dicyandiamide. Lu et al ${ }^{18}$ developed a phosphorus based durable flame retardant using urea, ammonium polyphosphate and dicyandiamide as a catalyst. From the literature review, it can be concluded that most of the efficient flame retardants involve toxic substances, such as halogens, formaldehyde, and dicyandiamide.
Trimethyl phosphate is a phosphorus based, halogen free, and formaldehyde free flame retarding agent, which has been reported as an effective flame retarding agent. Chung et al. ${ }^{19}$ studied the flame retardant properties of polyurethane using TMP. They used TMP for the degradation of polyurethane and indicated that the degraded product was changed to phosphorus containing oligourethanes. Tsunekawa et al. ${ }^{20}$ used TMP to improve the conductivity of lithiumion batteries. Wang et al. ${ }^{21}$ used TMP to decrease the flammability of lithium-ion batteries. In addition, TMP has been used as fire retardant in plastics manufacturing. ${ }^{22}$ MacDonald et al..$^{23}$ used TMP as flame retardant and concluded that the TMP is a good alternative to halogenated flame retardants. Hence, TMP can be used as an effective ingredient in flame retardant recipes, if its performance can be enhanced for cotton fabric.

Typically, crosslinkers are used to enhance the durability and certain other performance properties of cotton fabric. Nevertheless, most of the cross-linkers reported in the literature are toxic and contain formaldehyde. However, succinic acid is a bio-based formaldehyde free alternative finishing agent for cotton fabrics. ${ }^{24-25}$ Chen and Wang $^{26}$ used succinic acid as crosslinking agent for cotton cellulose using nano titanium dioxide as a catalyst and achieved an effective crosslinking reaction between succinic acid and cellulose. Several studies also reported the use of glyoxal as a formaldehyde free crosslinker for cotton fabrics. ${ }^{27-28}$ Lee and $\mathrm{Kim}^{28}$ treated cotton fabrics with a glyoxal-glycol mixture as a formaldehyde free durable press finish by the pad-dry-cure method and indicated improved whiteness, good strength retention, and good wrinkle recovery angle. Fouda et al. ${ }^{29}$ treated cotton fabric with glyoxal and indicated good tensile strength and antibacterial activity in the presence of chitosan. Glyoxal has many advantages, such as wide availability, low cost, good functionality, and good solubility in water. ${ }^{30}$ Kittinaovarat et $a l .^{30}$ treated fabric with glyoxal and indicated better durable press performance and antibacterial ability than those of fabric treated with chitosan. The reaction between glyoxal and urea makes DHEU (dihydroxy ethylene urea), which reacts with formaldehyde to make dimethylol dihydroxy ethylene urea (DMDHEU). DMDHEU and its modified products are the most widely used resins in the textile industry. ${ }^{23}$ However, they release carcinogenic formaldehyde, which is a great 
concern for brands and consumers. This paper uses potassium persulfate as initiator. $\mathrm{Choi}^{31}$ used potassium persulfate as a free radical initiator for the polymerization of a formaldehyde free durable press finish for cotton fabrics. They indicated good properties. El-Shafei et $a l .^{32}$ used potassium persulfate as a free radical initiator to polymerize the chitosan and butyl acrylate for cotton fabrics.

This paper uses TMP with two sets of recipes. Succinic acid was polymerized with TMP and potassium persulfate in the first set of recipes, while the urea-glyoxal mixture was polymerized with TMP in the second set of recipes under various conditions. The performance of the proposed flame retardant recipes was compared against the Pyrovatex based flame retardant recipes.

\section{EXPERIMENTAL}

In this research, $100 \%$ bleached cotton fabric samples were used in all the recipes. The bleached cotton fabric was purchased from Kamal Textile Faisalabad, Pakistan. The proposed new recipes used trimethyl phosphate (TMP) as halogen free flame retarding agent, sodium hypophosphite (SHP) as catalyst for succinic acid recipes, succinic acid (SA), urea (U), and glyoxal (G) as formaldehyde free crosslinkers, potassium persulfate (PPS) as initiator, and acetic acid and sodium bicarbonate to adjust $\mathrm{pH}$. All these chemicals for the proposed new recipes were purchased from Sigma Aldrich. All the chemicals were laboratory grade and were used as received without any purification. For comparison purpose, the Pyrovatex based commercial recipes used Pyrovatex $\mathrm{CP}$ new (PVTX) as commercial flame retardant obtained from Huntsman. Knittex-CHN (CHN) as formaldehyde based catalyst and phosphoric acid (PA) as enhancer were obtained from Huntsman.

The polymerization was performed under normal atmosphere, inert atmosphere, and nitrogen atmosphere. Inert atmosphere means vacuum condition, in which all the air is pumped out. In nitrogen atmosphere, the vacuum is first created by removing all the air and then nitrogen is filled into the flask.

Two separate sets of recipes were developed based on different crosslinkers. In the first set of recipes, the succinic acid was used as crosslinker with TMP (Table 2 ). In the second set of recipes, the combination of urea and glyoxal was used as crosslinker with TMP (Table 3). Table 2 and Table 3 provide full details about all the recipes developed for the cotton fabric samples. After the polymerization of one hour, the resultant flame retardant recipes were applied on the cotton fabric samples, using the padding process at $80 \%$ pick-up. The percentage values for the fire retardant in the tables (1-5) represent fire retardant concentration in water. After padding, the fabric was dried at $100{ }^{\circ} \mathrm{C}$ for three minutes and cured at $180{ }^{\circ} \mathrm{C}$ for two minutes. Then, the fabric was washed with $0.5 \%$ detergent solution at the $80 \%$ pick-up and later dried at $100{ }^{\circ} \mathrm{C}$ for three minutes.

Before testing, all the fabric samples were conditioned for 24 hours at $20{ }^{\circ} \mathrm{C}$ temperature $\left(\mathrm{T}{ }^{\circ} \mathrm{C}\right)$ and $65 \%$ relative humidity. The polymerization recipes were optimized considering the char-length and charwidth that were determined using the vertical burning test (BS 5438 Test 2B). Then, the following tests were performed on some selected recipes: limiting oxygen index (LOI \%) (ASTM D2863) by using LOI apparatus (YZS-100A), crease recovery angle in degrees (CRA) (BS EN 22313 test method) by using a Shirley crease recovery tester (SH-149), air permeability retention (\%) (ASTM D737) by the air permeability apparatus, model HY0461L, warp-wise shrinkage (\%) and weft-wise shrinkage (\%) (AATCC test method 135), smoldering cigarette test before and after five washes (minutes) (EN 1021), phosphorus concentration (ppm) (using Olsen's method), formaldehyde content in fabric (ppm), energy dispersive X-ray spectroscopy (EDX) analysis, antimicrobial testing (AATCC 147 test method) and scanning electron microscopy (SEM) analysis (after four minutes of gold coating) performed by using a Seron SEM model AIS1800C, Korea. Fourier transform infrared spectroscopy (FTIR) analysis (32 background scans in the wavelength range from 650 to $4000 \mathrm{~cm}^{-1}$ ) was performed by using Agilent CARY 630 apparatus. The TGA of samples was performed to record the mass loss during heating from $25^{\circ} \mathrm{C}$ to 600 ${ }^{\circ} \mathrm{C}$, at a heating rate of $10{ }^{\circ} \mathrm{C} / \mathrm{min}$. A NETZSCH TG 209F1 Libra (Germany) evolution analyzer was used to perform TGA.

\section{RESULTS AND DISCUSSION}

This section summarizes and interprets the results obtained after synthesis and application of the two sets of proposed recipes. The proposed recipes were compared against two commercial recipes involving Pyrovatex $\mathrm{CP}$ new and phosphoric acid. Besides, the effect of using only TMP or only a crosslinker (i.e. succinic acid, urea, or glyoxal) was tested under different concentrations. When using only TMP or a crosslinker, the fabric samples burned completely (Table 1).

Table 2 summarizes the char-length and charwidth for the recipes involving succinic acid and TMP. Under normal atmosphere (Case 1), the catalyst and initiator were not used, and the temperature was different for each recipe. In this case, the samples burned fully for each recipe. In Case 2 to Case 5, the polymerization was performed in nitrogen atmosphere. In Case 2, the 
TMP quantity, succinic acid quantity, and the temperatures for all the recipes were kept identical to those in Case 1. In Case 2, the samples burned fully for each recipe. In Case 3, the temperature was kept constant at $75{ }^{\circ} \mathrm{C}$, and the effects of incorporating the catalyst and the initiator were evaluated. It is important to mention here that the catalyst is essential for carboxylic acids, like succinic acid, as reported by other researchers. Similarly, during our fire retardant polymerization, it was also concluded that the catalyst is essential.

In recipe TS11, the catalyst was used, but no initiator. For this recipe, the sample burned fully. Using $0.5 \%$ initiator (PPS) provided the best charlength (recipe TS13). This optimum quantity was used in Case 4, which included variable temperatures. In this case, the concentrations of TMP, catalyst, crosslinker, and initiator were the same as in recipe TS13 in Case 3. In Case 4, recipe TS17 provides superior char-length to that of the other recipes with temperatures of $75{ }^{\circ} \mathrm{C}$ (recipe TS17 and recipe TS13 are identical). Hence, $75{ }^{\circ} \mathrm{C}$ is still the optimum temperature for the best char-length. It may be due to the fact that below $75{ }^{\circ} \mathrm{C}$, like $50{ }^{\circ} \mathrm{C}$ or lower, the temperature is too low for the polymerization to start under optimum conditions, and may be at $90{ }^{\circ} \mathrm{C}$ or above, certain side reactions occur, which is not desired.

Hence, this optimum temperature was used to evaluate the effects of variable concentrations of different chemicals in the recipes (Case 5). In recipe TS20, when the concentration of TMP was kept identical as in the best recipe selected previously and the concentrations of the catalyst, crosslinker, and initiator were decreased. The char-length and char-width were inferior to those of recipe TS17 or TS13. Recipe TS21 is the same as recipe TS17 or TS13. In recipe TS22, the concentrations of the catalyst, crosslinker, and initiator were increased. Still, recipe TS21 (or TS17 or TS13) gave the best char-length and char-width. In recipe TS23, the quantity of TMP was decreased to $50 \%$ and the concentrations of other chemicals were the same as in recipe TS21 (or TS17 or TS13). Recipe TS23 gave 16\% higher char-length than TS21 (or TS17 or TS13). In recipe TS24, the quantity of TMP was increased to $33 \%$ and the concentrations of the other chemicals were the same as in recipe TS21 (or TS17 or TS13). Recipe TS24 gave 1\% worse char-length than TS21 (or TS17 or TS13). Hence, recipe TS21 (or TS17 or TS13) was the best recipe under nitrogen atmosphere.

In Case 6, the polymerization was performed in inert atmosphere. In this atmosphere, all the recipes were kept the same as in Case 4. Under inert atmosphere, the recipe TS27 provided the best char-length. Still, the recipe TS21 (or TS17 or TS13) provided superior char-length and charwidth under nitrogen atmosphere to those of recipe TS27 under inert atmosphere. Hence, the nitrogen environment is more favorable in the case of succinic acid.

Table 3 summarizes the char-length and charwidth for the recipes involving the polymerization of TMP with urea and glyoxal. Polymerization under each atmosphere with different temperatures and constant $\mathrm{pH}$ provided good char-length. However, nitrogen atmosphere provided the best char-length (Case 1 to Case 3, in Table 3). Recipe TGU7 provided the best charlength at $40{ }^{\circ} \mathrm{C}$. This optimum temperature was used to test the effect of variable $\mathrm{pH}$ under nitrogen atmosphere (Case 4). Still, recipe TGU7 provided the best char-length. It is important to note that recipe TGU7 and recipe TGU17 are the same. Hence, this recipe provided the optimum values for $\mathrm{pH}$ during polymerization, as well as during application on the cotton samples. In Case 4 , the sample burned fully at other $\mathrm{pH}$ values. In Case 5, the concentrations of TMP, urea, and glyoxal were changed under the nitrogen atmosphere and optimum temperature. Still, recipe TGU7 (or TGU17 or TGU23) provided the best char-length. Hence, the nitrogen atmosphere provided the best recipe.

For the first set of recipes involving polymerization of TMP with succinic acid, the best selected recipe was TS21 (or TS17 or TS13). For the second set of recipes involving polymerization of TMP with urea and glyoxal, the best selected recipe was TGU23 (or TGU7 or TGU17). Both selected recipes provided an acceptable char-length. It can be observed that the best recipe with urea and glyoxal provided $61 \%$ superior char-length to that of the best recipe with succinic acid. It can be noted that one more recipe with urea and glyoxal (TGU2) under normal atmosphere provided $36 \%$ superior char-length and $41 \%$ superior char-width to those of the best recipe with succinic acid. 
Table 1

Char-length and char-width corresponding to recipes with Pyrovatex, TMP, urea, and glyoxal

\begin{tabular}{|c|c|c|c|c|c|c|c|c|}
\hline Recipe & Flame retardant & Catalyst & Crosslinker & $\begin{array}{l}\text { Polymerization } \\
\text { temperature }\left({ }^{\circ} \mathrm{C}\right)\end{array}$ & Initiator & $\begin{array}{l}\text { Weight add- } \\
\text { on }(\%)\end{array}$ & $\begin{array}{l}\text { Char-length } \\
(\mathrm{mm})\end{array}$ & $\begin{array}{l}\text { Char-width } \\
\text { (mm) }\end{array}$ \\
\hline PVTX1 & $20 \%$ PVTX & $1.5 \% \mathrm{CHN}$ & $2.5 \%$ PA & - & - & 9.3 & $98 \pm 0.2$ & $32 \pm 0.1$ \\
\hline PVTX2 & $40 \%$ PVTX & $2.2 \% \mathrm{CHN}$ & $6 \% \mathrm{PA}$ & - & - & 9.4 & $64 \pm 0.1$ & $28 \pm 0.1$ \\
\hline TMP1 & $5 \% \mathrm{TMP}$ & - & - & - & - & 9.1 & Fully burned & Fully burned \\
\hline TMP2 & $10 \%$ TMP & - & - & - & - & 9.2 & Fully burned & Fully burned \\
\hline TMP3 & $20 \%$ TMP & - & - & - & - & 9.4 & Fully burned & Fully burned \\
\hline TMP4 & $40 \%$ TMP & - & - & - & - & 9.4 & Fully burned & Fully burned \\
\hline SA1 & - & - & $5 \% \mathrm{SA}$ & - & - & 9.1 & Fully burned & Fully burned \\
\hline SA2 & - & - & $10 \% \mathrm{SA}$ & - & - & 9.2 & Fully burned & Fully burned \\
\hline SA3 & - & - & $15 \% \mathrm{SA}$ & - & - & 9.4 & Fully burned & Fully burned \\
\hline Urea1 & - & - & $5 \%$ urea & - & - & 9.1 & Fully burned & Fully burned \\
\hline Urea2 & - & - & $10 \%$ urea & - & - & 9.3 & Fully burned & Fully burned \\
\hline Urea3 & - & - & $15 \%$ urea & - & - & 9.2 & Fully burned & Fully burned \\
\hline Glyoxal 1 & - & - & $5 \%$ glyoxal & - & - & 9.1 & Fully burned & Fully burned \\
\hline Glyoxal 2 & - & - & $10 \%$ glyoxal & - & - & 9.4 & Fully burned & Fully burned \\
\hline Glyoxal 3 & - & - & $15 \%$ glyoxal & - & - & 9.4 & Fully burned & Fully burned \\
\hline
\end{tabular}


Table 2

Char-length and char-width corresponding to recipes with TMP and succinic acid

\begin{tabular}{|c|c|c|c|c|c|c|c|c|}
\hline Recipe & $\begin{array}{l}\text { Flame } \\
\text { retardant }\end{array}$ & Catalyst & $\begin{array}{l}\text { Cross- } \\
\text { linker }\end{array}$ & $\begin{array}{c}\mathrm{T} \\
\left({ }^{\circ} \mathrm{C}\right)\end{array}$ & Initiator & $\begin{array}{c}\text { Weight add- } \\
\text { on }(\%)\end{array}$ & $\begin{array}{l}\text { Char-length } \\
\text { (mm) }\end{array}$ & $\begin{array}{l}\text { Char-width } \\
\text { (mm) }\end{array}$ \\
\hline \multicolumn{9}{|c|}{ Case 1. Polymerization under normal atmosphere, at different temperatures, with no catalyst/initiator } \\
\hline TS1 & $10 \%$ TMP & - & $10 \% \mathrm{SA}$ & 25 & - & 9.3 & Fully burned & Fully burned \\
\hline TS2 & $10 \%$ TMP & - & $10 \% \mathrm{SA}$ & 50 & - & 9.1 & Fully burned & Fully burned \\
\hline TS3 & $10 \%$ TMP & - & $10 \% \mathrm{SA}$ & 75 & - & 9.2 & Fully burned & Fully burned \\
\hline TS4 & $10 \%$ TMP & - & $10 \% \mathrm{SA}$ & 90 & - & 9.1 & Fully burned & Fully burned \\
\hline TS5 & $10 \%$ TMP & - & $10 \% \mathrm{SA}$ & 100 & - & 9.2 & Fully burned & Fully burned \\
\hline \multicolumn{9}{|c|}{ Case 2. Polymerization under nitrogen atmosphere, at different temperatures, with no catalyst/initiator } \\
\hline TS6 & $10 \%$ TMP & - & $10 \% \mathrm{SA}$ & 25 & - & 9.2 & Fully burned & Fully burned \\
\hline TS7 & $10 \%$ TMP & - & $10 \% \mathrm{SA}$ & 50 & - & 9.4 & Fully burned & Fully burned \\
\hline TS8 & $10 \%$ TMP & - & $10 \%$ & 75 & - & 9.4 & Fully burned & Fully burned \\
\hline S9 & $10 \%$ TMP & - & $10 \%$ & 90 & - & 9.1 & Ful & Full \\
\hline TS10 & $10 \%$ TMP & - & $10 \% \mathrm{SA}$ & 100 & - & 9.3 & Fully burned & Fully burned \\
\hline \multicolumn{9}{|c|}{ Case 3. Polymerization under nitrogen atmosphere, at optimum temperature, with catalyst and initiator } \\
\hline TS11 & $10 \%$ TMP & $8 \%$ SHP & $10 \% \mathrm{SA}$ & 75 & - & 9.1 & Fully burned & Fully burned \\
\hline & $10 \%$ TMP & & & 75 & & 9.4 & & \\
\hline TS13 & 10\% TMP & & $10 \% \mathrm{SA}$ & 75 & & 9.2 & & \\
\hline TS14 & $10 \%$ TMP & $8 \%$ SHP & $10 \% \mathrm{SA}$ & 75 & $0.6 \%$ PPS & 9.4 & $81 \pm 0.4$ & $31 \pm 0.5$ \\
\hline \multicolumn{9}{|c|}{ Case 4. Polymerization under nitrogen atmosphere, at different temperatures, with catalyst and initiator } \\
\hline TS15 & $10 \%$ TMP & $8 \%$ SHP & $10 \% \mathrm{SA}$ & 25 & $0.5 \%$ PPS & 9.2 & $105 \pm 0.4$ & \\
\hline & $10 \%$ TMP & $8 \%$ & $10 \%$ & 50 & & 9.1 & & \\
\hline S17 & 10\% TMP & $8 \%$ SHP & $10 \%$ & 75 & PS & 9.2 & & .1 \\
\hline & $10 \%$ TMP & & $10 \% \mathrm{~S}$ & 90 & & 9.3 & & \\
\hline TS19 & $10 \%$ TMP & $8 \%$ SHP & $10 \% \mathrm{SA}$ & 100 & $0.5 \%$ PPS & 9.3 & $89 \pm 0.4$ & $29 \pm 0.3$ \\
\hline \multicolumn{9}{|c|}{ Case 5. Polymerization under nitrogen atmosphere, at optimum temperature and different concentrations } \\
\hline TS20 & $10 \%$ TMP & $4 \%$ SHP & $5 \% \mathrm{SA}$ & 75 & $0.25 \%$ PPS & 9.4 & $79 \pm 0.8$ & \\
\hline TS21 & $10 \%$ TMP & $8 \%$ SHP & $10 \% \mathrm{SA}$ & 75 & $0.50 \%$ PPS & 9.2 & \pm 0.3 & $\mathbf{0 . 1}$ \\
\hline TS22 & $10 \%$ TMP & $12 \%$ SHP & $15 \% \mathrm{SA}$ & 75 & $0.75 \%$ PPS & 9.3 & $78 \pm 0.9$ & $27 \pm 0.7$ \\
\hline TS23 & $5 \%$ TMP & $8 \%$ SHP & $10 \% \mathrm{SA}$ & 75 & $0.50 \%$ PPS & 9.3 & $91 \pm 0.1$ & \\
\hline TS24 & $15 \%$ TMP & $8 \%$ SHP & $10 \% \mathrm{SA}$ & 75 & $0.50 \%$ PPS & 9.3 & $77 \pm 0.3$ & $27 \pm 0.6$ \\
\hline \multicolumn{9}{|c|}{ Case 6. Polymerization under inert (vacuum) atmosphere, at different temperatures, with catalyst and initiator } \\
\hline & $10 \%$ TMP & & $10 \% \mathrm{SA}$ & 25 & & 9.2 & $114 \pm 0.3$ & \\
\hline TS26 & 10\% TMP & $8 \%$ SHP & $10 \% \mathrm{SA}$ & 50 & $0.5 \%$ PPS & 9.3 & $6 \pm 0.4$ & $56 \pm 0.5$ \\
\hline TS27 & $10 \%$ TMP & $8 \%$ SHP & $10 \% \mathrm{SA}$ & 75 & $0.5 \%$ PPS & 9.1 & $105 \pm 0.4$ & \\
\hline TS28 & $10 \%$ TMP & $8 \%$ SHP & $10 \% \mathrm{SA}$ & 90 & $0.5 \%$ PPS & 9.4 & $119 \pm 0.5$ & $36 \pm 0.6$ \\
\hline TS29 & $10 \%$ TMP & $8 \%$ SHP & $10 \% \mathrm{SA}$ & 100 & $0.5 \%$ PPS & 9.4 & $118 \pm 0.6$ & $41 \pm 0.4$ \\
\hline
\end{tabular}

It may be due to the fact that succinic acid is a dicarboxylic acid and definitely will be less effective than a tricarboxylic acid, like citric acid, while DHEU has the capability of forming efficient ether linkages.

The $\mathrm{pH}$ plays an important role in polymerization, therefore, it was evaluated in Case 4. Typically, DHEU synthesis and polymerization reactions are carried out under alkaline conditions. In this paper, when polymerization was carried out under acidic conditions (TGU18 and TGU19), the treated cotton fabric samples burned completely. Usually, crosslinkers are applied onto cotton fabric under acidic conditions. In this paper, when the application $\mathrm{pH}$ was changed to alkaline conditions
(TGU16 and TGU19), the treated fabric burned completely. Hence, recipe TS21 (or TS17 or TS13) and recipe TGU23 (or TGU7 or TGU17) were selected for further testing. Table 4 summarizes the results of the tests performed on these specific recipes.

\section{Limiting oxygen index (LOI)}

It can be observed that, when only a single crosslinker or TMP was used, the LOI value was too low. The fabric samples treated with Pyrovatex provided good LOI (recipes PVTX1 and PVTX2). However, the LOIs for recipe TGU23 (with urea and glyoxal) and recipe TS21 (with succinic acid) were comparable with that of the $40 \%$ Pyrovatex based recipe, as demonstrated 
by the char-length and char-width results as well. The Pyrovatex based recipe with lower concentration $(20 \%)$ performed inferior to the proposed recipes. Hence, the proposed recipes provide the best alternatives to the formaldehyde based Pyrovatex.

\section{Smoldering cigarette test}

The recipe involving only a single crosslinker or TMP, or $20 \%$ Pyrovatex (PVTX1), showed less performance in the smoldering cigarette test, compared with recipe PVTX2 (with 40\% Pyrovatex), recipe TGU23 (with urea and glyoxal) and recipe TS21 (with succinic acid).
Therefore, this test result is also in line with the char-length and LOI tests.

Before washing, recipe TGU23 (with urea and glyoxal) and recipe TS21 (with succinic acid) showed flame-resistance comparable to that of the recipe having $40 \%$ Pyrovatex and superior to that of the $20 \%$ Pyrovatex based recipe. After five washing cycles, the Pyrovatex based fabric showed $1 \%$ decrease in flame resistance, while recipe TGU23 (with urea and glyoxal) and recipe TS21 (with succinic acid) showed a more significant decrease in flame resistance, related to the smoldering cigarette test. Recipe TGU23 (with urea and glyoxal) showed better flame resistance than recipe TS21 (with succinic acid).
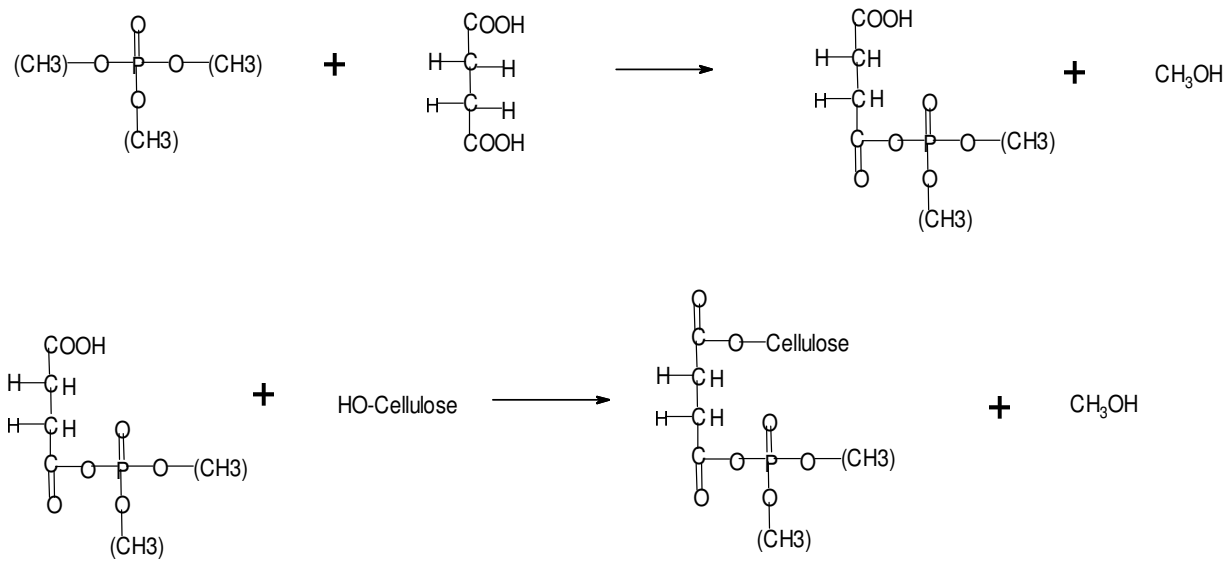

Figure 1: Reaction mechanism of TMP and succinic acid with cotton

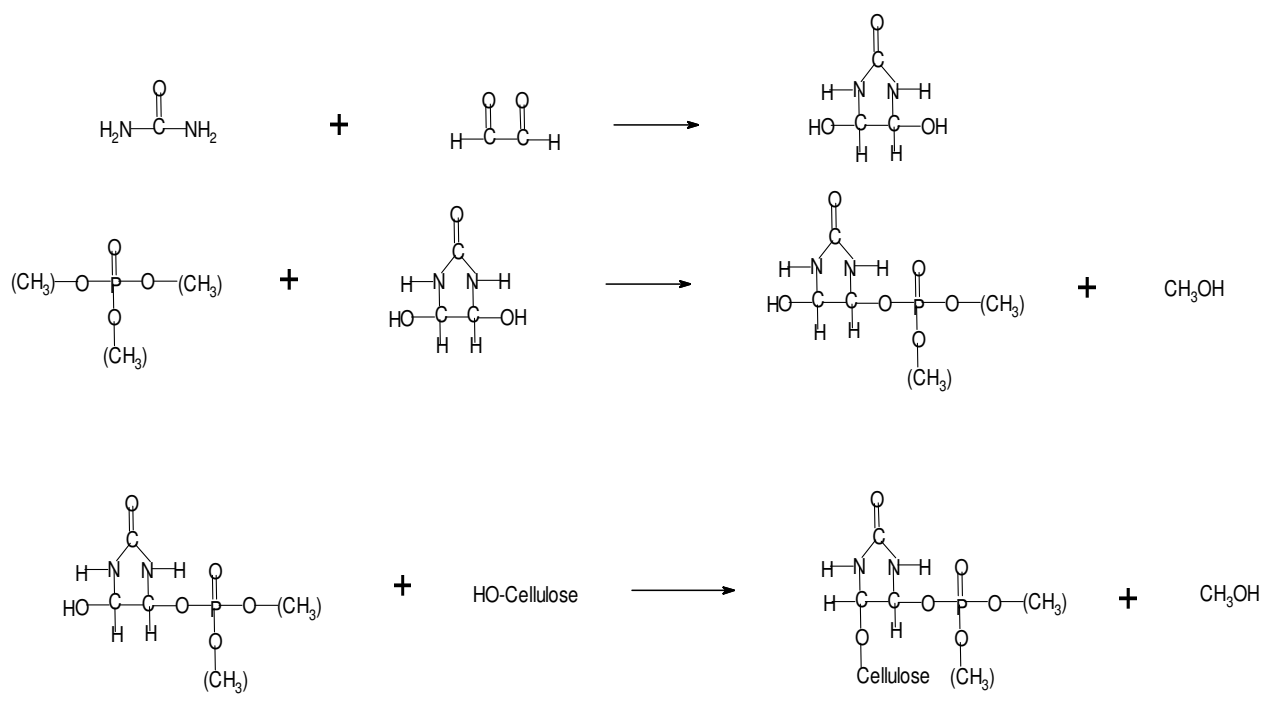

Figure 2: Reaction mechanism of TMP, urea and glyoxal with cellulose 
HAJI GHULAM QUTAB et al.

Table 3

Char-length and char-width corresponding to recipes with TMP, urea, and glyoxal

\begin{tabular}{|c|c|c|c|c|c|c|c|c|}
\hline Recipe & $\begin{array}{c}\text { Flame } \\
\text { retardant }\end{array}$ & Crosslinker & $\begin{array}{c}\mathrm{pH} \text { during } \\
\text { polymerization }\end{array}$ & $\begin{array}{l}\mathrm{pH} \text { during } \\
\text { application }\end{array}$ & $\begin{array}{c}\mathrm{T} \\
\left({ }^{\circ} \mathrm{C}\right)\end{array}$ & $\begin{array}{c}\text { Weight add-on } \\
(\%)\end{array}$ & $\begin{array}{l}\text { Char-length } \\
\text { (mm) }\end{array}$ & $\begin{array}{l}\text { Char-width } \\
(\mathrm{mm})\end{array}$ \\
\hline \multicolumn{9}{|c|}{ Case 1. Polymerization with normal atmosphere, different temperatures, and constant $\mathrm{pH}$} \\
\hline TGU1 & $10 \%$ TMP & \multirow{5}{*}{$10 \%$ urea, $10 \%$ glyoxal } & 9.5 & 4.5 & 30 & 9.2 & $115 \pm 0.5$ & $19 \pm 0.7$ \\
\hline TGU2 & 10\% ТМР & & 9.5 & 4.5 & 40 & 9.4 & $49 \pm 0.5$ & $16 \pm 0.2$ \\
\hline TGU3 & $10 \%$ TMP & & 9.5 & 4.5 & 60 & 9.1 & $129 \pm 0.2$ & $34 \pm 0.5$ \\
\hline TGU4 & $10 \%$ TMP & & 9.5 & 4.5 & 80 & 9.1 & $96 \pm 0.1$ & $31 \pm 0.6$ \\
\hline TGU5 & $10 \%$ TMP & & 9.5 & 4.5 & 90 & 9.3 & $69 \pm 0.8$ & $19 \pm 0.7$ \\
\hline \multicolumn{9}{|c|}{ Case 2. Polymerization with nitrogen atmosphere, different temperatures, and constant $\mathrm{pH}$} \\
\hline TGU6 & $10 \%$ TMP & \multirow{5}{*}{$10 \%$ urea, $10 \%$ glyoxal } & 9.5 & 4.5 & 30 & 9.1 & $79 \pm 0.6$ & $19 \pm 0.5$ \\
\hline TGU7 & $10 \%$ TMP & & 9.5 & 4.5 & 40 & 9.3 & $30 \pm 0.1$ & $36 \pm 0.4$ \\
\hline TGU8 & $10 \%$ TMP & & 9.5 & 4.5 & 60 & 9.2 & $99 \pm 0.9$ & $18 \pm 0.8$ \\
\hline TGU9 & $10 \%$ TMP & & 9.5 & 4.5 & 80 & 9.2 & $71 \pm 0.5$ & $33 \pm 0.5$ \\
\hline TGU10 & $10 \%$ TMP & & 9.5 & 4.5 & 90 & 9.3 & $75 \pm 0.4$ & $36 \pm 0.7$ \\
\hline \multicolumn{9}{|c|}{ Case 3. Polymerization with inert (vacuum) atmosphere, different temperatures, and constant $\mathrm{pH}$} \\
\hline TGU11 & $10 \%$ TMP & \multirow{5}{*}{$10 \%$ urea, $10 \%$ glyoxal } & 9.5 & 4.5 & 30 & 9.2 & $140 \pm 0.8$ & $35 \pm 0.3$ \\
\hline TGU12 & 10\% ТМР & & 9.5 & 4.5 & 40 & 9.3 & $59 \pm 0.5$ & $39 \pm 0.3$ \\
\hline TGU13 & $10 \%$ TMP & & 9.5 & 4.5 & 60 & 9.1 & $93 \pm 0.6$ & $36 \pm 0.4$ \\
\hline TGU14 & $10 \%$ TMP & & 9.5 & 4.5 & 80 & 9.1 & $125 \pm 0.8$ & $20 \pm 0.2$ \\
\hline TGU15 & $10 \%$ TMP & & 9.5 & 4.5 & 90 & 9.3 & $75 \pm 0.6$ & $26 \pm 0.3$ \\
\hline \multicolumn{9}{|c|}{ Case 4. Polymerization with nitrogen atmosphere, optimum temperature, and variable $\mathrm{pH}$} \\
\hline TGU16 & $10 \%$ TMP & \multirow{4}{*}{$10 \%$ urea, $10 \%$ glyoxal } & 9.5 & 9.5 & 40 & 9.1 & Fully burned & Fully burned \\
\hline TGU17 & $10 \%$ TMP & & 9.5 & 4.5 & 40 & 9.3 & $\mathbf{3 0 \pm 0 . 1}$ & $36 \pm 0.4$ \\
\hline TGU18 & $10 \%$ TMP & & 4.5 & 4.5 & 40 & 9.2 & Fully burned & Fully burned \\
\hline TGU19 & $10 \%$ TMP & & 4.5 & 9.5 & 40 & 9.2 & Fully burned & Fully burned \\
\hline \multicolumn{9}{|c|}{ Case 5. Polymerization with nitrogen atmosphere, different concentrations, and optimum temperature } \\
\hline TGU20 & $10 \%$ TMP & $5 \%$ urea, $5 \%$ glyoxal & 9.5 & 4.5 & 40 & 9.4 & $180 \pm 0.5$ & $26 \pm 0.6$ \\
\hline TGU21 & $10 \%$ TMP & $15 \%$ urea, $15 \%$ glyoxal & 9.5 & 4.5 & 40 & 9.2 & $56 \pm 0.4$ & $24 \pm 0.7$ \\
\hline TGU22 & $5 \%$ TMP & & 9.5 & 4.5 & 40 & 9.3 & $56 \pm 0.8$ & $24 \pm 0.4$ \\
\hline TGU23 & 10\% TMP & $10 \%$ urea, $10 \%$ glyoxal & 9.5 & 4.5 & 40 & 9.3 & $30 \pm 0.1$ & $36 \pm 0.1$ \\
\hline TGU24 & $15 \%$ TMP & & 9.5 & 4.5 & 40 & 9.1 & $31 \pm 0.2$ & $36 \pm 0.2$ \\
\hline
\end{tabular}


Table 4

Performance of selected fabric samples at fundamental tests

\begin{tabular}{|c|c|c|c|c|c|c|c|c|c|}
\hline Test & $\begin{array}{l}\text { No } \\
\text { sample }\end{array}$ & $\begin{array}{l}\text { Control } \\
\text { sample }\end{array}$ & $\begin{array}{c}10 \% \\
\text { succinic } \\
\text { acid }\end{array}$ & $\begin{array}{c}10 \% \text { urea } \\
\text { and glyoxal }\end{array}$ & $\begin{array}{l}10 \% \\
\text { TMP }\end{array}$ & $\begin{array}{c}\text { Recipe PVTX1 } \\
\text { (with 20\% } \\
\text { Pyrovatex) }\end{array}$ & $\begin{array}{c}\text { Recipe PVTX2 } \\
\text { (with } 40 \% \\
\text { Pyrovatex) }\end{array}$ & $\begin{array}{c}\text { Recipe TGU23 } \\
\text { (with urea and } \\
\text { glyoxal) }\end{array}$ & $\begin{array}{c}\text { Recipe TS21 } \\
\text { (with succinic } \\
\text { acid) }\end{array}$ \\
\hline Limiting oxygen index (LOI) (\%) & N/A & 18.3 & 18.3 & 18.4 & 19.6 & 27.5 & 33 & 33.9 & 32.8 \\
\hline $\begin{array}{l}\text { CRA (degree) crease recovery } \\
\text { angle (CRA) }\end{array}$ & N/A & 138 & 192 & 171 & 143 & 160 & 170 & 195 & 188 \\
\hline Air permeability retention $(\%)$ & N/A & 100 & 81 & 83 & 87 & 85.5 & 69.3 & 83.8 & 78 \\
\hline Warp-wise shrinkage $(\%)$ & N/A & 7.7 & 1.6 & 1.3 & 3.6 & 3.3 & 2.8 & 2.6 & 2.7 \\
\hline Weft-wise shrinkage (\%) & N/A & 6.1 & 1.5 & 1.3 & 3.4 & 3.3 & 2.8 & 2.1 & 2.6 \\
\hline $\begin{array}{l}\text { Smoldering cigarette test before } \\
\text { washing (minutes) }\end{array}$ & N/A & 10 & 12 & 11 & 12 & 17 & 25 & 27 & 24 \\
\hline $\begin{array}{l}\text { Smoldering cigarette test after } \\
\text { washing (minutes) }\end{array}$ & N/A & 10 & 12 & 11 & 12 & 16 & 24 & 16 & 16 \\
\hline Phosphorus concentration (ppm) & N/A & 0 & 0 & 0 & 26276 & 17689 & 34344 & 30955 & 28987 \\
\hline $\begin{array}{l}\text { Formaldehyde content in fabric } \\
(\mathrm{ppm})\end{array}$ & N/A & 0 & 0 & 0 & 0 & 32 & 41 & 0 & 0 \\
\hline
\end{tabular}

N/A - not applicable or available 


\section{Crease recovery angle (CRA)}

The recipes containing only a specific crosslinker indicated better CRA than the recipes with the flame-retarding agent (TMP). This indicates that the succinic acid and the ureaglyoxal mixture are effective crosslinkers for cotton, and TMP alone does not contribute to an improved CRA. These results are quite obvious as the main function of crosslinkers is to improve the crease recovery angle. However, using only a specific crosslinker performed worse in terms of other properties (i.e. LOI, smoldering cigarette test, char-length, and char-width), which are important for flame-retardancy. Hence, the addition of a crosslinker to the flame-retarding agent enhanced the flame-retardancy and CRA simultaneously. Succinic acid formed ester bonds with TMP and cotton, as shown in Figure 1. It is mainly due to this covalent bonding that the treated fabric's crease recovery is higher than that of untreated cotton fabric. However, in the case of urea and glyoxal, it first forms dihydroxyethlene urea, which then forms ether linkages with TMP and cotton, as exhibited in Figure 2. Therefore, treated cotton fabric (TMP and urea-glyoxal) exhibited superior crease recovery to that of untreated cotton fabric, mainly due to the newly developed ether linkage. Pyrovatex also improved CRA due its covalent bonding with cotton fabric (i.e. recipe PVTX1 and recipe PVTX2). However, recipe TGU23 (TMP with urea and glyoxal) and recipe TS21 (TMP with succinic acid) indicated better CRA than the Pyrovatex based recipes.

\section{Air permeability retention}

Air permeability retention for the untreated cotton fabric sample was considered the best $(100 \%)$. Air permeability decreases as the chemical concentration increases because of increased blockage of air passage through the coated fabric. The air permeability retention values of all the selected recipes, except recipe PVTX2, were comparable to each other. One reason that recipe PVTX2 resulted in less air permeability retention is its concentration of chemicals (i.e. 40\% Pyrovatex, 2.2\% CHN catalyst, and $6 \%$ phosphoric acid). Recipe TGU23 (TMP with urea and glyoxal) showed 7\% higher air permeability than recipe TS21 (TMP with succinic acid).

\section{Shrinkage}

The recipes containing only a crosslinker indicated the least shrinkage, and the recipe containing only TMP (i.e. flame-retarding agent) indicated the worse shrinkage. It is quite obvious that the more significant the crosslinking of cotton, the lower will be the shrinkage. Recipes TGU23 (TMP with urea and glyoxal) and recipe TS21 (TMP with succinic acid) indicated considerably less shrinkage than the Pyrovatex based flame retardants (recipes PVTX1 and PVTX2). It is clear that the crosslinkers (i.e. succinic acid, urea, glyoxal) decreased the shrinkage in the proposed recipes.

\section{Phosphorus concentration and formaldehyde content in fabric}

In the phosphorus based flame retardants, the phosphorus is the key element that improves the flame retardancy. Succinic acid, urea, and glyoxal do not contain any phosphorus. Formaldehyde based recipes (recipes PVTX1 and PVTX2) contain acceptable amount of phosphorus, depending on the quantity of Pyrovatex. For a good flame retardant, $17000 \mathrm{ppm}$ is the recommended quantity of phosphorus. The best formaldehyde-free recipes, TGU23 (with urea and glyoxal) and TS21 (with succinic acid), contain more than the acceptable amount of phosphorus. Concerning the formaldehyde content in the cotton fabric, recipe PVTX1 (with 20\% Pyrovatex) indicated $32 \mathrm{ppm}$ formaldehyde and recipe PVTX2 (with 40\% Pyrovatex) indicated 41 ppm formaldehyde. In contrast, the best two recipes, TGU23 (with urea and glyoxal) and TS21 (with succinic acid), indicated zero formaldehyde.

\section{Fourier transform infrared spectroscopy (FTIR)}

FTIR analysis was also performed on selected seven recipes. For recipe TS21 (Fig. 3c), a prominent ester peak was observed at $1248 \mathrm{~cm}^{-1}$, and P-O-C stretch can easily be detected at 920$1088 \mathrm{~cm}^{-1}$. It can be observed that there is no such peak of the ester for the remaining recipes (Figs. 3 and 4). In addition, for recipe TGU23, a prominent ether peak was observed at $1250 \mathrm{~cm}^{-1}$ (Fig. 4d).

\section{TGA analysis}

Figure 5 presents the TGA curves of untreated cotton fabric, cotton fabric treated with $10 \%$ SA, $10 \%$ urea, $10 \%$ glyoxal, $10 \%$ TMP, recipe TS21 (best recipe of TMP with SA), recipe TGU23 (best recipe of TMP with urea and glyoxal) and $20 \%$ Pyrovatex. The untreated cotton fabric (see curve 1), $10 \%$ SA treated cotton fabric (curve 2), 
$10 \%$ urea (curve 3) and $10 \%$ glyoxal (curve 4) have decomposition temperatures starting at 337 ${ }^{\circ} \mathrm{C}$. The cotton fabrics treated with the fire retardants have lower decomposition temperature because of the catalytic dehydration of cellulose by the fire retardants. The decomposition temperature of recipe TGU23 treated fabric (306 ${ }^{\circ} \mathrm{C}$, curve 7) was higher than that corresponding to recipes TS21 $\left(300^{\circ} \mathrm{C}\right.$, curve 6), $20 \%$ Pyrovatex $\left(280{ }^{\circ} \mathrm{C}\right.$, curve 8$)$ and TMP $10 \%\left(250{ }^{\circ} \mathrm{C}\right.$, curve
5). However, the amount of char formed was higher for recipe TGU23 treated fabric (39.98\%, curve 7) than for recipe TS21 (34.98\%, curve 6), $20 \%$ Pyrovatex (28.79\%, curve 8 ) and $10 \%$ TMP (23.56\%, curve 5). Overall, recipe TGU23 treated cotton fabric exhibited better thermal stability than that treated with recipe TS21, 20\% Pyrovatex and $10 \%$ TMP. These results are in line with the best char length and width exhibited by TGU23 treated fabric.

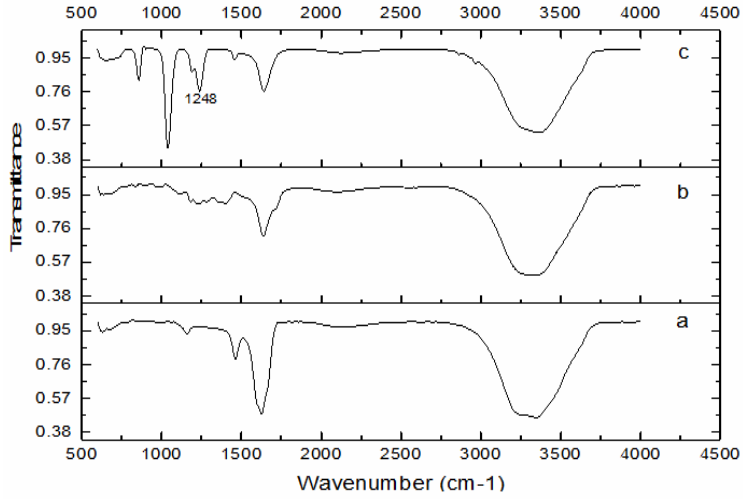

Figure 3: FTIR analysis of samples treated with (a) $10 \%$ $\mathrm{TMP}$, (b) $10 \% \mathrm{SA}$, (c) recipe $\mathrm{TS} 21$

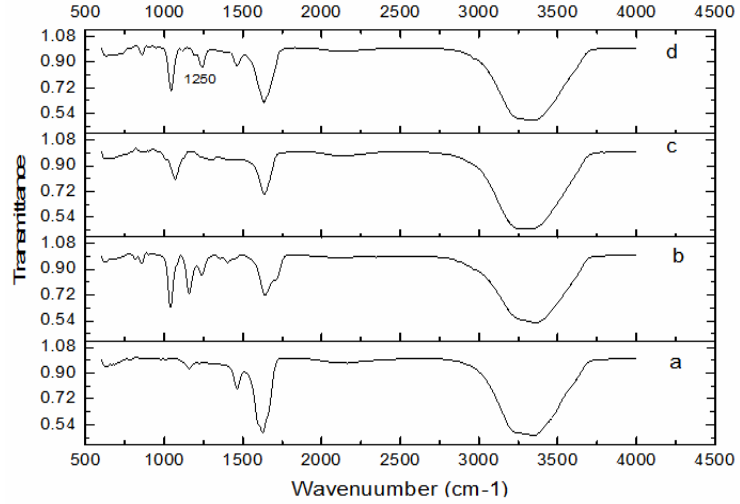

Figure 4: FTIR analysis of samples treated with (a) $10 \%$ TMP, (b) 10\% urea, (c) 10\% glyoxal, (d) TGU23

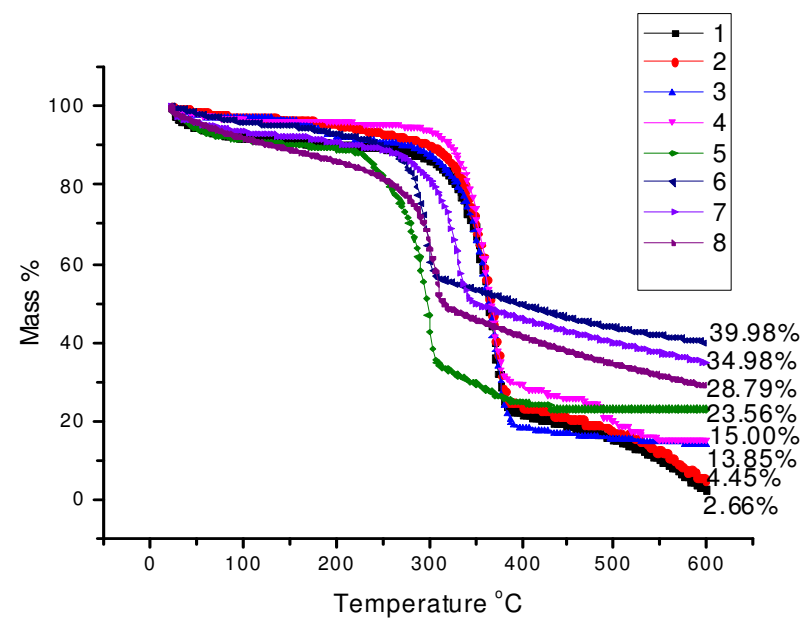

Figure 5: TGA analysis of (1) untreated cotton fabric, and samples treated with (2) $10 \%$ SA, (3) $10 \%$ urea, (4) 10\% glyoxal, (5) 10\% TMP, (6) recipe TGU23, (7) recipe TS21, (8) 20\% PVTX

\section{Energy dispersive X-ray spectroscopy (EDX) analysis \\ EDX analysis is used to obtain X-ray spectra} of solids. It is a vital technique to identify the elements in the materials. The EDX analysis was performed on seven recipes, as described in Figure 6. It can be observed that there is no peak of phosphorus in the control fabric or in the recipe with a crosslinker (i.e. 10\% succinic acid, $10 \%$ urea and $10 \%$ glyoxal). Hence, using only crosslinker did not impart flame retardancy. In contrast, prominent phosphorus peaks can be observed when using only TMP and for the best recipes TS21 (with succinic acid) and TGU23 (with urea and glyoxal). Hence, EDX analysis confirmed the presence of phosphorus in the proposed flame retardant recipes. Recipe TGU23 (with urea and glyoxal) showed higher 


\section{HAJI GHULAM QUTAB et al.}

phosphorus of $23.32 \%$, which is responsible for its superior fire retardancy as well.

\section{SEM analysis}

SEM analysis was performed on three selected samples, specifically, untreated cotton, the sample

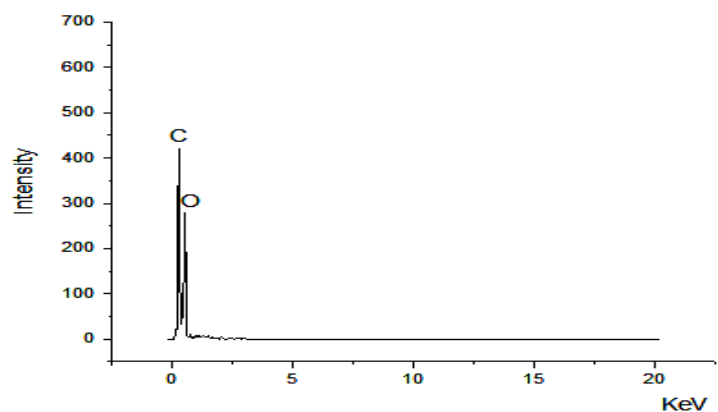

(a)

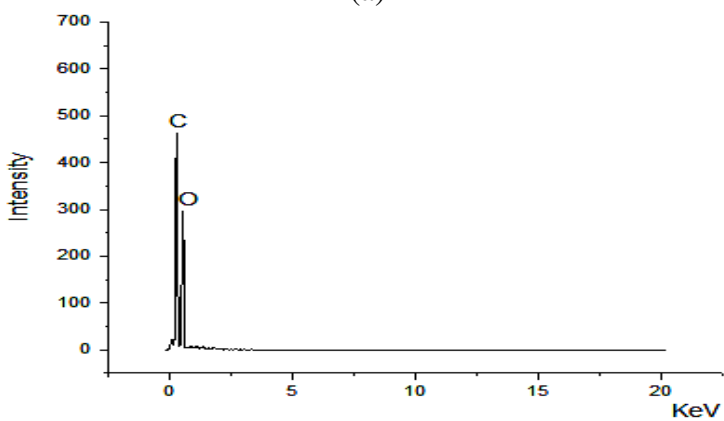

(c)

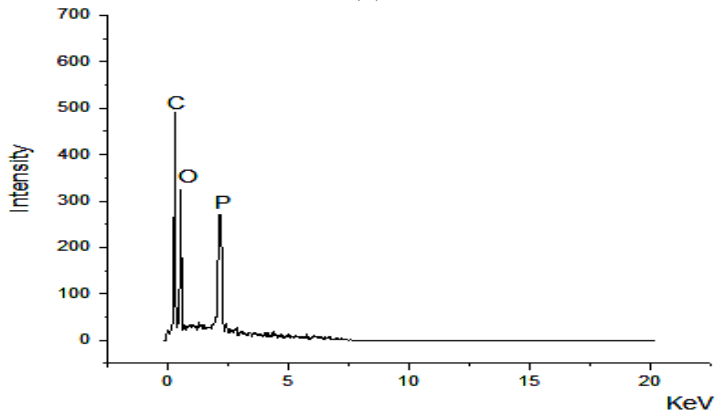

(e)

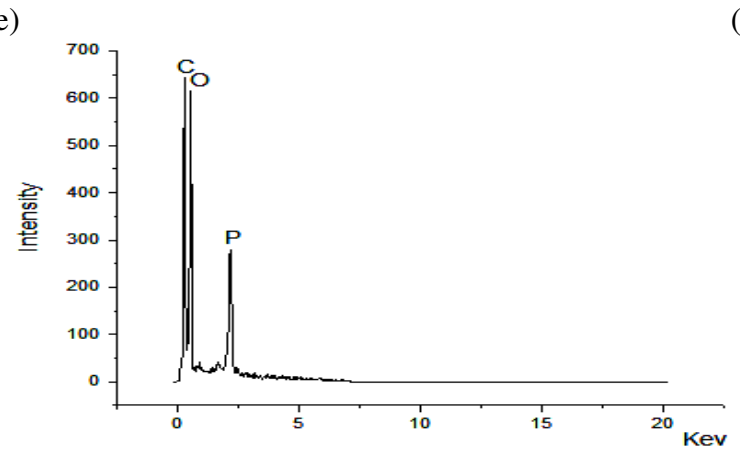

(g)

Figure 6: EDX analysis of (a) control fabric, and samples treated with (b) $10 \%$ succinic acid, (c) $10 \%$ urea, (d) 10\% glyoxal, (e) 10\% TMP, (f) recipe TS21 (with succinic acid), (g) recipe TGU23 (with urea and glyoxal) treated with recipe TS21 (the best recipe using TMP and succinic acid) and the fabric treated with TGU23 (the best recipe using TMP with urea and glyoxal). It can be observed that the surface of the untreated cotton sample is clear and smooth.

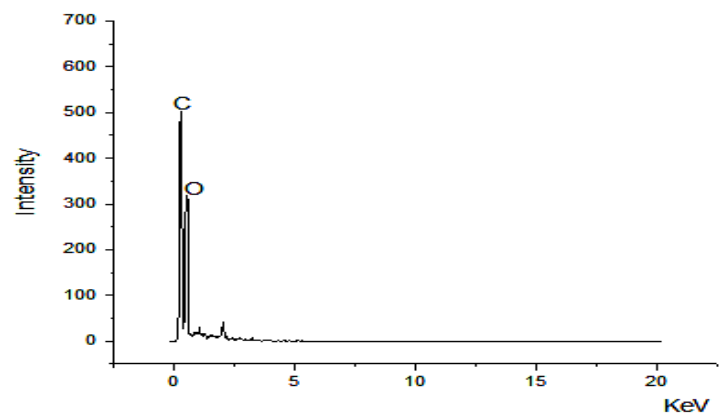

(b)

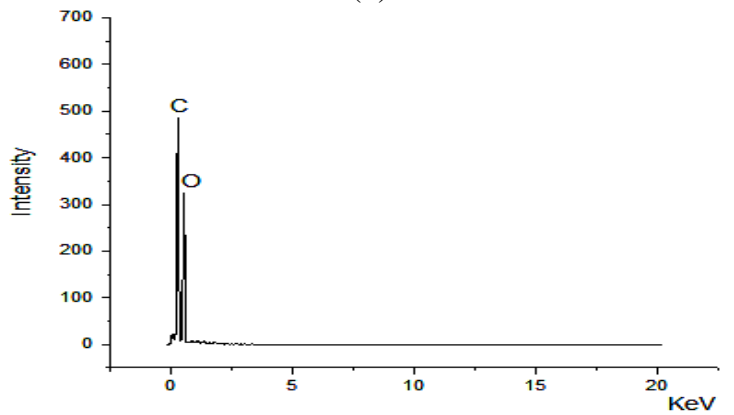

(d)

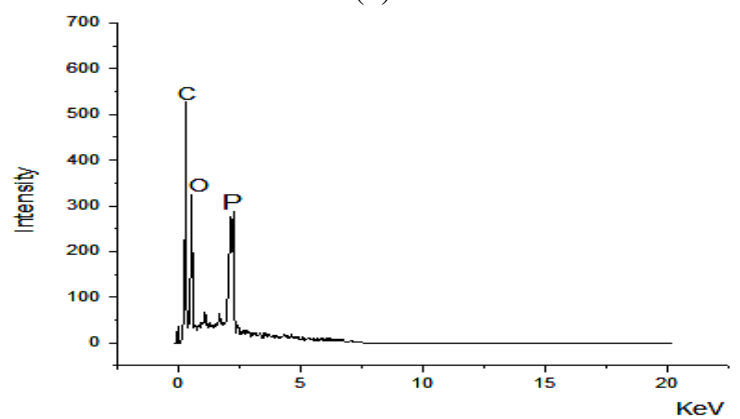

(f) 


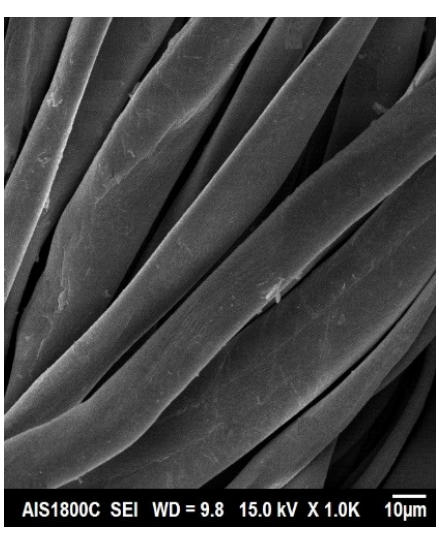

(a)

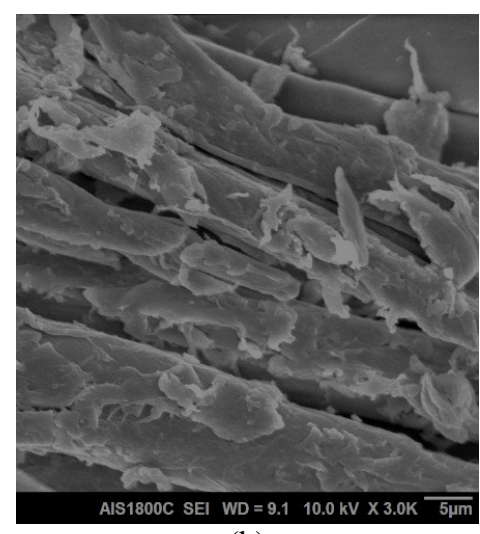

(b)

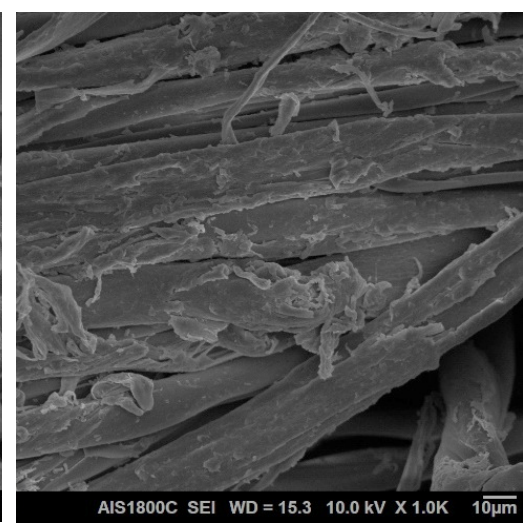

(c)

Figure 7: SEM images of (a) untreated cotton fabric sample, and samples treated with (b) recipe TS21 (with succinic acid), (c) recipe TGU23 (with urea and glyoxal)

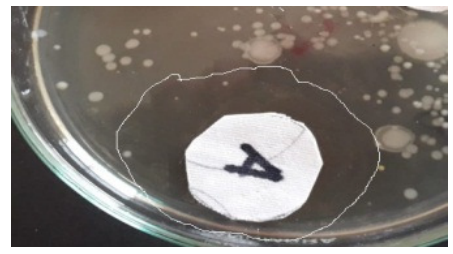

(a)

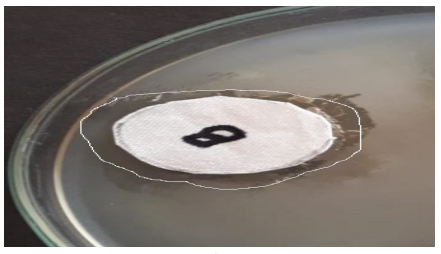

(b)

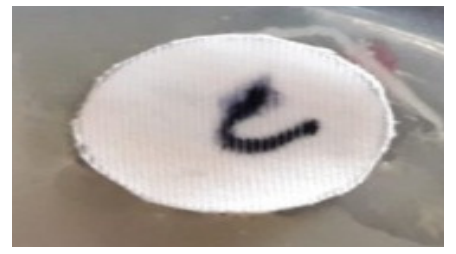

(c)

Figure 8: Antimicrobial test of (a) recipe TS21 (with succinic acid), (b) recipe TGU23 (with urea and glyoxal), (c) untreated cotton fabric

However, the surface of the sample treated with the above two best polymerization involving recipes reveals the coating on the fabric, which is evidence that the fire retardant has been successfully applied onto the cotton fabric (Fig. 7).

\section{Antimicrobial performance of finished cotton fabric}

The antimicrobial test was performed on the untreated cotton sample, and on samples treated with recipe TS21 (the best recipe using TMP with succinic acid) and TGU23 (the best recipe using TMP with urea and glyoxal). It can be observed that the untreated cotton sample showed no antimicrobial activity, as expected. However, the sample treated with the best recipe using TMP with succinic acid (TS21) exhibited $0.91 \mathrm{~mm}$ width of the clear zone of inhibition, and the best recipe using TMP with urea and glyoxal (TGU23) showed $0.34 \mathrm{~mm}$ width of the clear zone of inhibition (Fig. 8). Hence, the proposed recipes showed good antimicrobial performance.

\section{CONCLUSION}

This research successfully develops two efficient flame retardant recipes, using trimethyl phosphate (TMP) with bio-based crosslinker succinic acid, as well as TMP with urea-glyoxal under different polymerization atmospheres and conditions. When treated under normal atmosphere and without using catalyst or initiator, the fabric sample was fully burned for each assessed recipe involving succinic acid and TMP. Similarly, when nitrogen atmosphere was used for the treatment, the fabric sample was fully burned for each of the prepared recipes. However, the addition of catalyst (SHP) and initiator (PPS) to the recipes with TMP and succinic acid improved the flame retardancy. The optimum result in the case of succinic acid was obtained when $10 \%$ succinic acid was polymerized with 10\% TMP, along with catalyst $8 \%$ SHP and $0.5 \%$ PPS at 75 ${ }^{\circ} \mathrm{C}$ under nitrogen atmosphere. The char-length for this best recipe was higher than that corresponding to the $40 \%$ Pyrovatex based recipe and lower than that of the 20\% Pyrovatex based recipe. Similarly, in the case of polymerization between TMP, urea, and glyoxal, the best results were obtained under nitrogen atmosphere. The above-mentioned optimized recipes also exhibited improved performance in terms of LOI, shrinkage control, antimicrobial and crease recovery properties. EDX analysis confirmed the presence 
of adequate phosphorus amounts in the two best recipes. SEM analysis indicated the successful application of the identified recipes on the fabric samples. Both recipes are non-toxic and formaldehyde free. However, the succinic acid based recipe is more sustainable, as it is a biobased product. Hence, the proposed recipes provide potential alternatives to the existing hazardous flame retardants for textile materials.

\section{REFERENCES}

1 E. A. Brunner and K. M. DeLuca, Argum. Advocacy, $\quad$ 52, $281 \quad$ (2016), https://doi.org/10.1080/00028533.2016.11821875

2 F. Caniato, M. Caridi, L. Crippa and A. Moretto, Int. J. Prod. Econ., 135, 659 (2012), https://doi.org/10.1016/j.ijpe.2011.06.001

3 S. M. Mostashari and S. Z. Mostashari, Cellulose Chem. Technol., 43, $455 \quad$ (2009), http://www.cellulosechemtechnol.ro/pdf/CCT9-102009/p.455-460.pdf

4 S. M. Mostashari, Cellulose Chem. Technol., 43, 199

http://www.cellulosechemtechnol.ro/pdf/CCT4-62009/199-204.pdf

A. Abou-Okeil, S. M. El-Sawy and F. A. AbdelMohdy, Carbohyd. Polym., 92, 2293 (2013), https://doi.org/10.1016/j.carbpol.2012.12.008

6 W. W. Gao, G. X. Zhang and F. X. Zhang, Cellulose, $\quad$ 22, $2787 \quad$ (2015), https://doi.org/10.1007/s10570-015-0641-z

7 A. Khandual, in Procs. Green Fashion, 2016, pp. $171-227$ Springer, Singapore https://doi.org/10.1007/978-981-10-0245-8_6 8 X. Wang, C. Lu and C. Chen, J. Appl. Polym. Sci., 131, 1 (2014), https://doi.org/10.1002/app.40584

9 F. Carosio, A. Di Blasio, F. Cuttica, J. Alongi and G. Malucelli, Ind. Eng. Chem. Res., 53, 3917 (2014), https://doi.org/10.1021/ie404089t

10 S. Basak, K. K. Samanta, S. Saxena, S. K. Chattopadhyay, R. Narkar et al., Pol. J. Chem. Technol., $\quad 17, \quad 123 \quad$ (2015), https://www.degruyter.com/downloadpdf/j/pjct.2015.1 7.issue-1/pjct-2015-0018/pjct-2015-0018.pdf

11 D. Wang, L. Zhong, C. Zhang, F. Zhang and G. Zhang, Cellulose, 25, $5479 \quad$ (2018), https://doi.org/10.1007/s10570-018-1964-3

12 D. Zheng, J. Zhou, L. Zhong, F. Zhang and G. Zhang, Cellulose, 23, 2211 (2016), https://doi.org/10.1007/s10570-016-0949-3

13 F. Zhang, W. Gao, Y. Jia, Y. Lu and G. Zhang, Carbohyd. Polym., 199, $256 \quad$ (2018), https://doi.org/10.1016/j.carbpol.2018.05.085

${ }_{14}$ M. Mohsin, S. W. Ahmad, A. Khatri and B. Zahid, J. Clean. Prod., 51, $191 \quad$ (2013), https://doi.org/10.1016/j.jclepro.2013.01.031
15 D. Zheng, J. Zhou, Y. Wang, F. Zhang and G. Zhang, Cellulose, 25, 787 (2018), https://doi.org/10.1007/s10570-017-1543-Z

16 Y. Lu, Y. Jia, Y. Zhou, J. Zou, G. Zhang et al., Carbohyd. Polym., 201, $438 \quad$ (2018), https://doi.org/10.1016/j.carbpol.2018.08.078

17 Y. Jia, Y. Hu, D. Zheng, G. Zhang, F. Zhang et al., Cellulose, 24, 1159 (2017), https://doi.org/10.1007/s10570-016-1163-z

${ }_{18}$ Y. Lu, Y. Jia, G. Zhang and F. Zhang, Cellulose, 25, 5389 (2018), https://doi.org/10.1007/s10570-0181930-0

${ }_{19}$ Y. J. Chung, Y. Kim and S. Kim, J. Ind. Eng. Chem., $\quad \mathbf{1 5}, \quad 888 \quad$ (2009), https://doi.org/10.1016/j.jiec.2009.09.018

20 H. Tsunekawa, A. Narumi, M. Sano, A. Hiwara, M. Fujita et al., J. Phys. Chem. B, 107, 10962 (2003), https://doi.org/10.1021/jp0300546

21 X. Wang, E. Yasukawa and S. Kasuya, J. Electrochem. Soc., 148, $1066 \quad$ (2001), http://jes.ecsdl.org/content/148/10/A1058.short 22 X. Wang, E. Yasukawa and S. Kasuya, $J$. Electrochem. Soc., 148, $1058 \quad$ (2001), http://jes.ecsdl.org/content/148/10/A1066.short

23 M. A. MacDonald, T. M. Jayaweera, E. M. Fisher and F. C. Gouldin, Combust. Flame, 116, 166 (1999), https://doi.org/10.1016/S0010-2180(98)00034-0

24 L. Karimi, M. Mirjalili, M. E. Yazdanshenas and A. Nazari, Photochem. Photobiol., 86, 1030 (2010), https://doi.org/10.1111/j.1751-1097.2010.00756.x

${ }_{25}$ V. A. Dehabadi, V. A. Buschmann and J. S. Gutmann, Text. Res. J., 83, 1974 (2013), https://doi.org/10.1177/0040517513483857

26 C. C. Chen and C. C. Wang, J. Sol-Gel. Sci. Techn., 40, 31 (2006), https://doi.org/10.1007/s10971-0068319-5

27 E. S. Lee and S. I. Kim, Fiber. Polym., 5, 230 (2004), https://doi.org/10.1007/BF02903005

28 E. S. Lee and S. I. Kim, J. Appl. Polym. Sci., 96, 975 (2005), https://doi.org/10.1002/app.20751

29 M. M. Fouda, A. El Shafei, S. Sharaf and A. Hebeish, Carbohyd. Polym., 77, 651 (2009), https://doi.org/10.1016/j.carbpol.2009.02.017

30 S. Kittinaovarat, P. Kantuptim and T. Singhaboonponp, J. Appl. Polym. Sci., 100, 1372 (2006), https://doi.org/10.1002/app.23635

31 H. M. Choi, Text. Res. J., 62, 614 (1992), https://doi.org/10.1177/004051759206201010

32 A. El-Shafei, S. Shaarawy and A. Hebeish, Polym.Plast. Technol., 44, $1523 \quad$ (2005), https://www.tandfonline.com/doi/abs/10.1080/0360255 0500207840 